and King had a melting point $10^{\circ}$ lower than that of pure ascorbic acid, and thus certainly contained more than 0.1 per cent impurity. This question, whether the activity is due to a definite substance or to contaminations, applies to all research on vitamins and is usually one of the most difficult problems to solve.

There is, however, much circumstantial evidence in favour of the identity of vitamin $\mathrm{C}$ and ascorbic acid. The parallelism in distribution and behaviour under experimental conditions, and the quantitative correspondence of the antiscorbutic activity of plant juice and its ascorbic acid content, point in this direction. Harris has shown that this quantitative correspondence holds also for the adrenal cortex with its high ascorbic acid content. Svirbely has shown that the ascorbic acid disappears from the gland very readily on vitaminfree diet, thus demonstrating the inability of the animal to build up this substance. Svirbely has also shown that our ascorbic acid, prepared from the adrenal gland, retained its antiscorbutic activity after five recrystallisations. Work on purely chemical lines alone could give direct and definite evidence of the identity of the vitamin and ascorbic acid. Unfortunately, the great scarcity of the material rendered such work impossible. Fresh adrenal glands, a convenient source for preparations, were not available in the necessary quantity, and all our efforts to prepare ascorbic acid from lemons, oranges, tomatoes, or cabbages on a large scale have failed.

In the third step in our work these difficulties were overcome and the way opened for direct chemical work, providing definite evidence for the identity of vitamin $\mathrm{C}$ and ascorbic acid. This progress we owe to the discovery that local varieties of Hungarian red pepper (Capsicum annuum) contain the acid not only in relatively large quantities but also under conditions which make its isolation exceedingly simple. It is due to this fact that during the last few months Svirbely and I have been able to prepare a full pound of crystalline ascorbic acid for chemical studies. Unhampered thus by the lack of material, we could set out with L. v. Vargha to study derivatives of ascorbic acid, an investigation which has led to the preparation of a monoacetone derivative. This substance seemed to be almost ideally suited for our purpose. It forms big, beautiful crystals with great ease and is stable in anhydrous solution, from which it can be recrystallised without difficulty. After due recrystallisation the original acid can be recovered unchanged by simply boiling it in water for a few minutes. Since the acetone derivative does not hydrolyse in cold water immediately, it was found in the antiscorbutic experiment to be but moderately active. The ascorbic acid, recovered from the recrystallised derivative, was fully active, a definite evidence for the identity of ascorbic acid and the vitamin.

The last and perhaps the most difficult step towards the definite chemical identification of the vitamin is the establishment of the chemical constitution of ascorbic acid. The possibility of preparing ascorbic acid in quantity has also opened the way for the chemical analysis. It was a great privilege for my American collaborator Svirbely and myself to be allowed to supply material to Prof. Haworth at Birmingham and Prof. Karrer at Zurich for this analysis.

The work of the laboratories at Zurich and Birmingham has clearly brought out that ascorbic acid is, confirming my original findings, a simple substance, consisting of 6 carbon, 8 hydrogen and 6 oxygen atoms; it contains one carboxy group, but is, however, not a member of the uronic acid series, and thus is not a hexuronic acid. Two of the carbon atoms are present as $\mathrm{C}=\mathrm{O}$ groups forming a keto or aldehyde group with strong enolisation. One carbon is present as $\mathrm{CH}_{2}$. The remaining two carbon and oxygen atoms are present as alcoholic groups. In this way the essential features of the molecule are cleared up and there remains only to ascertain the relative position of these groups.

It is hoped that the fact that the vitamin is a specific constituent of the adrenal cortex, from which it disappears on vitamin-free diet, will open up many fascinating problems to research and may contribute to the deeper understanding of the relation of hormones and vitamins.

There is one aspect of these investigations on which I look with pride and gratitude. This work has been made possible only by the closest international collaboration. It has been helped by Dutch, English and American hospitality and generosity. At present it is aided by the Josiah Macy, Jr. Foundation.

\title{
Geology in the Life of a Nation
}

$\mathrm{T}$ HE Indian Science Congress held its twentieth annual meeting this year at Patna under the presidency of Dr. L. L. Fermor, Director of the Geological Survey of India. In his presidential address Dr. Fermor refers to some matters of general interest in the history of the Indian Science Congress, which is modelled on the lines of the British Association, and, like that body, meets annually at different towns.

The initial meeting that led to the formation of the Congress was held in 1912 in the rooms of the Asiatic Society of Bengal and that Society has since taken the general responsibility for the organisation of the Congress year after year. Until 1931 the Congress had no permanent organisation, but a constitution was then adopted whereby it did become a continuous organisation under the title of the Indian Science Congress Association with a roll of permanent members-though the close association with the Asiatic Society of Bengal 
is to be maintained. Dr. Fermor appeals to generous donors to remember the Indian Science Congress now that it has an independent existence, since it is hoped that in the future it may have funds for financing special items of research.

Special mention is made of the new periodical Current Science, the first issue of which as a monthly journal appeared in July 1932. This periodical has been modelled on the lines of NaTuRE and there has been no lack of material suitable for publication, but the financial position of the new venture at present leaves much to be desired, though this all-India journal of science can be self-supporting with a minimum of five hundred subscribers.

It is certainly very clear that the Indian Science Congress has fulfilled a want. At the first meeting there were 79 members, a presidential address was given, and 35 papers were read, and the published proceedings occupied eight pages of print. At the nineteenth meeting in 1931 the number of full and associate members was 690 and of student members 183. There were ten presidential addresses, general and sectional, and 693 papers were communicated occupying 467 pages of Proceedings.

In choosing as the subject for his presidential address, "The Place of Geology in the Life of a Nation", Dr. Fermor has left the sting of his remarks to the tail. All the countries of Europe, excluding Russia, Finland, Scandinavia, Poland, Greece and Turkey can be fitted into the area of India excluding Burma. The Geological Surveys of the various European countries have staffs numbering more than 250, of which 78 are employed in Germany and 52 in Great Britain. Yet for the adequate geological survey of a corresponding area, the staff of the Geological Survey of India has just been cut down in a most drastic way. It now has only 24 officers, 6 of whom are employed in Burma, leaving only 18 for the whole of the vast area of India. It is small wonder, therefore, that the Director of the Geological Survey should seek to analyse the position which geology should occupy in the life of a nation. In so doing he interprets geology as geographical evolution and states that "geography is the branch of geology that describes the particular shape and form of the earth's surface at the present time".

Although there are few geographers who would accept this definition, they would heartily agree with Dr. Fermor upon the necessity for a detailed study of that portion of the human environment which comes within the domain of the geologist. The position of the capital of India has been dictated by the physical structure of the subcontinent, which in turn depends on its geology. Similarly, the position of the commercial capital, Calcutta, dependent as it is on the nature and extent of its hinterland, has been similarly determined. The black earth region that forms the natural hinterland of Bombay and provides the Bombay cotton mills with their huge supplies of raw cotton, depends in turn upon the existence there of the black soil derived in the main from the Deccan lavas. The close correspondence between the political map of Europe and the orographical and geological is emphasised and it is in particular pointed out how the less stable political units of Europe are those which are less clearly natural geographical or geological units. "India is fortunate, however, in that the general geological conditions have caused the inhabitants, in spite of their diversity of race, religion and language, to be welded after struggles through the ages into one political unit. As the national boundaries in central Europe, the boundaries between the provinces in India pay little attention in many cases to geological considerations. The province of Bihar and Orissa, for instance, . . . is an excellent example of the viola. tion of natural principles by provincial boundaries. But as long as the central political control remains, it does not matter seriously that the boundaries of our provinces take such little account of natural factors. Were the central control, however, removed and all political relationship to one general suzerain power severed, then the future history of India would again become as confused as it was in the past and as confused as that of Central Europe has been throughout the ages and promises to become again in the future."

This is truly the geographer's point of view and it is interesting to find it so clearly voiced by a geologist. There is an unhappy note when Dr. Fermor says towards the end of his address that "at present the scope for new employment for geologists in India has fallen almost to zero". He urges, however, the continued need for geological classes in university institutions as a "branch of general culture".

One cannot regret feeling that Dr. Fermor has not been able, because of his official position as director, to add point to his arguments by reciting some, at least, of the great work which has been carried out by the Geological Survey of which he is head. So it is to be feared that the reduction of this essential service in such an amazingly drastic fashion has passed without the notice that it should have attracted from men of science. For the Survey has a great and continuous record of work and it is to be hoped that under Dr. Fermor's guidance it will force an adequate recognition of its services to the country.

This is not the place for reciting what the Survey has done, but perhaps its Director may be able to remove what have in the past been two of the major criticisms: (1) the perhaps rather inadequate means of publication of the detailed mapping carried out by the officers, whose work in this respect remains unknown even to geologists in India itself, while there is apparently nowhere in Britain where the one-inch maps, on the preparation of which a large proportion of the officers' time is expended, can ever be consulted; (2) the serious time lag between field-work and publication, especially important where problems of economic geology are being investigated.

L. DUdLey Stamp. 